\title{
Article \\ Microstructure of Ag Nano Paste Joint and Its Influence on Reliability
}

\author{
Dongsheng Yang, Yilong Huang and Yanhong Tian *
}

check for updates

Citation: Yang, D.; Huang, Y.; Tian, Y. Microstructure of Ag Nano Paste Joint and Its Influence on Reliability. Crystals 2021, 11, 1537. https:// doi.org/10.3390/cryst11121537

Academic Editors: Zhan Sun,

Zhenwen Yang, Chun Li, Xiaoqing Si and Wei Guo

Received: 31 October 2021

Accepted: 3 December 2021

Published: 9 December 2021

Publisher's Note: MDPI stays neutral with regard to jurisdictional claims in published maps and institutional affiliations.

Copyright: (c) 2021 by the authors. Licensee MDPI, Basel, Switzerland. This article is an open access article distributed under the terms and conditions of the Creative Commons Attribution (CC BY) license (https:// creativecommons.org/licenses/by/ $4.0 /)$.
State Key Laboratory of Advanced Welding and Joining, Harbin Institute of Technology, Harbin 150001, China; yangds2021@hotmail.com (D.Y.); huangyilongde@outlook.com (Y.H.)

* Correspondence: tianyh@hit.edu.cn

\begin{abstract}
In this paper, the microstructure of Ag nano paste joint was investigated in pressure-less sintering conditions, and the influence of the microstructure on the joint's reliability was studied. Firstly, silver nanoparticles (Ag NPs) were synthesized using the redox reaction method. To tightly stack the Ag NPs in nano paste, Ag NPs with sizes of 30 50 nm and submicron-sized Ag particles were mixed. It was found that increasing the sintering temperature or sintering time can reduce the porosity of the bonding layer and the interfacial crack simultaneously, resulting in higher shear strength. When sintering at a temperature of $250^{\circ} \mathrm{C}$, a complete bonding interface was formed, with a $0.68 \mu \mathrm{m}$ interdiffusion layer. At a higher temperature $\left(300^{\circ} \mathrm{C}\right)$, the bonding interface reached $1.5 \mu \mathrm{m}$, providing $35.9 \pm 1.7 \mathrm{MPa}$ of shear strength. The reliability of the die attachment was analyzed under thermal shocking from $-65^{\circ} \mathrm{C}$ to $150{ }^{\circ} \mathrm{C}$ for 50 cycles. As the crack could quickly grow through the interfacial defects, the separation ratio was $85 \%$ and $67 \%$ when sintered at $150{ }^{\circ} \mathrm{C}$ and $200{ }^{\circ} \mathrm{C}$, respectively. Because of the reliable bonding interface between the die and the substrate, the $\mathrm{Ag}$ nano paste joint formed a slight crack on the edge of the die when sintering at $250{ }^{\circ} \mathrm{C}$. When the joint was sintered at $300{ }^{\circ} \mathrm{C}$, the small voids became large voids, which featured lower resistance to crack growth. Thus, instead of further improved reliability, the separation ratio increased to $37 \%$.
\end{abstract}

Keywords: Ag nano paste; microstructure; porosity; interfacial defects; reliability

\section{Introduction}

To meet the higher power density requirements of electronic devices, die attach materials are desirable to obtain both excellent heat dissipation capability and high working temperature [1,2]. For example, the operating temperature of electronics close to jet engines and power electronics in electric mobiles can reach $300^{\circ} \mathrm{C}$, or even $400{ }^{\circ} \mathrm{C}$ in some cases $[3,4]$. Traditional die attach materials are based on the principle of solid-liquid interdiffusion bonding, which features a high bonding temperature, over $500{ }^{\circ} \mathrm{C}$, and high thermal conductivity [5]. However, the material system and structural design of electronic products are increasingly complex. A novel die attachment material with moderate bonding temperature less than $300{ }^{\circ} \mathrm{C}$ and higher thermal dissipation ability is required.

Many researchers have searched for alternative materials, among which a promising material, based on silver nanoparticle (Ag NP) sintering, has attracted considerable interest [6]. This promising material is called Ag nano paste. It is composed of Ag NPs and organic additives. It has been proven that reducing the Ag NP size to the nanoscale of 10-100 $\mathrm{nm}$ reduces melting and sintering temperatures, enabling a low processing temperature for Ag nano paste $\left(<300{ }^{\circ} \mathrm{C}\right)$ and a high operating temperature for $\mathrm{Ag}$ nano paste joints compared to the melting point of $\mathrm{Ag}\left(960^{\circ} \mathrm{C}\right)$ [7].

To obtain a lower sintering temperature, researchers have focused on reducing the size of Ag NPs. At first, micron-sized Ag particles were synthesized [8]. However, pressure was generally required to achieve dense, higher conductive, and highly reliable sintered $\mathrm{Ag}$ joint at temperatures below $300{ }^{\circ} \mathrm{C}$. Subsequently, $\mathrm{Ag}$ NPs were investigated to replace Ag micron-sized Ag particles [9]. By further reducing the size of Ag NPs, the sintering 
temperature of $275^{\circ} \mathrm{C}$ was achieved with low pressure, of a few MPa [2]. The reducedsize Ag NPs also demonstrated high reliability in small power die attachments for hightemperature applications, where even pressure-less sintering was achieved. In recent years, studies have mainly focused on the sintering process. Sintering parameters, such as sintering pressure, sintering temperature profile, the type of organic materials in the paste, the size distribution of the particles, metallization on bonding substrates, and the atmosphere in which the sintering takes place, were considered to reduce the void in the joints and improve bonding force [10-12].

While many studies address the use of Ag nano paste in die attachment applications, few studies have been conducted to investigate the reliability of Ag nano paste joints. In this paper, the porosity and interfacial metallization of Ag nano paste joint was investigated. Next, thermal shocking tests were performed on the joint structures to compare their failure modes. Finally, the influence of the microstructure on the reliability of the joint was summarized.

\section{Materials and Methods}

$\mathrm{AgNO}_{3}, \mathrm{Na}_{3} \mathrm{C}_{6} \mathrm{H}_{5} \mathrm{O}_{7} \cdot 2 \mathrm{H}_{2} \mathrm{O}$, and $\mathrm{FeSO}_{4} \cdot 7 \mathrm{H}_{2} \mathrm{O}$ were used as precursors, dispersants, and reducing agents, respectively. All the chemicals were used as received without further purification. To observe the microstructure of the Ag nano paste joint, cross-section samples were prepared by mechanical polishing with $\mathrm{SiC}$ abrasive sandpaper (240\#, 800\#, 200\#, and $4000 \#)$, and then polished with a $1.0 \mu \mathrm{m}$ diamond suspension to eliminate surface scratches. A TESCAN Vega3 scanning electron microscope (SEM) operated at $10 \mathrm{kV}$ was used to obtain the microstructure of Ag nano paste joint. The shear strength of the Ag nano paste joint was tested by Dage 4000 . The reliability of the Ag nano paste joint was analyzed by using a thermal shock tester. The defects in the Ag nano paste joint were non-destructively tested by a scanning acoustic microscope (SAM) machine.

\section{Results and Discussion}

\subsection{Preparation of Ag Nano Paste}

The Ag NPs were prepared based on a previous method [13]. By controlling the reaction time duration, small size Ag NPs with diameters of 30-50 nm and large-size Ag NPs with diameters of 200-1000 nm were synthesized. Firstly, the Ag NP composite was prepared; it comprised small-size Ag NPs and large-size Ag NPs. Next, the Ag nano paste was prepared by mixing Ag NP composite and glycol using a mixing machine. The weight ratio of the small Ag NP to the large Ag NP to glycol was fixed at 40:55:5. Figure 1a schematically illustrates the composition of the mixed Ag NPs, and the corresponding microscopic morphology is presented in Figure 1b, in which uniform mixing of bimodal Ag NPs can be observed. The bimodal nano paste offers two main advantages. On the one hand, the added large-size Ag NPs can prevent agglomeration between small-size NPs. On the other hand, when sintered with the nano paste comprising monodispersed NPs, the sintered interface always suffers from high porosity. By contrast, the bimodal nano paste enables low packing density, thus improving the bonding strength between the die and the substrate. The connected large-size Ag NPs can form a frame, while small-size Ag NPs fill the gaps. As a result, dense sintered joints can be obtained. 

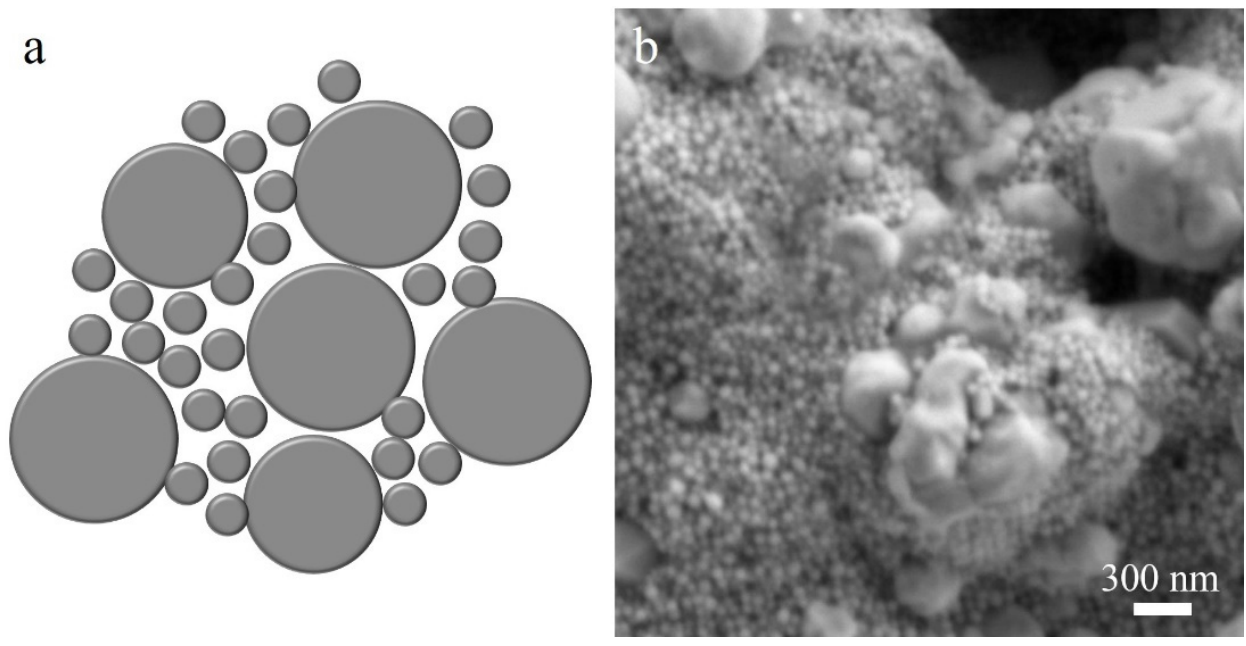

Figure 1. The Ag NP composite: (a) the schematic diagram; (b) the SEM image.

\subsection{Porosity Analysis of Ag Nano Paste Joint}

The porosity of the sintered joint is an important index for evaluating bonding quality. Hence, we counted the porosity of the sintered joint under different parameters by using software. Figure 2 presents the porosity of the joint after sintering bimodal nano paste for different times (60 min, $70 \mathrm{~min}, 80 \mathrm{~min}, 90 \mathrm{~min}, 100 \mathrm{~min}, 110 \mathrm{~min}$, and $120 \mathrm{~min}$ ) under different temperatures $\left(150{ }^{\circ} \mathrm{C}, 200^{\circ} \mathrm{C}, 250^{\circ} \mathrm{C}\right.$, and $\left.300{ }^{\circ} \mathrm{C}\right)$. It can be seen that the porosity of the joint decreases with the increase of the sintering time at a fixed sintering temperature, which can be attributed to the sufficient diffusion and fusion of adjacent Ag NPs. The porosity of the sintered joint, in addition, decreases with the increase in sintering temperature at a fixed sintering time, due to the faster atomic diffusion rate at higher temperatures. When the sintering temperature is $150{ }^{\circ} \mathrm{C}$, even after a long sintering time of $120 \mathrm{~min}$, the porosity is still high, up to $37 \%$. When the sintering temperature increases to $200{ }^{\circ} \mathrm{C}$, the porosity decreases to $31 \%$ after the same sintering time. When the sintering temperature increases to $250{ }^{\circ} \mathrm{C}$, the porosity further decreases (25\%). When the sintering temperature reaches $300^{\circ} \mathrm{C}$, the porosity of the joint sintered for $60 \mathrm{~min}$ is lower than the joint sintered at $150^{\circ} \mathrm{C}$ for $120 \mathrm{~min}$. This result indicates that the sintering temperature has a significant effect on porosity.

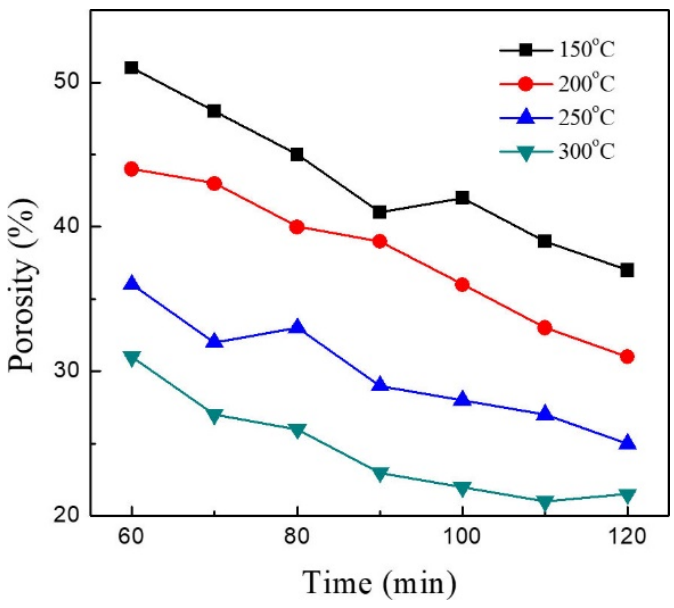

Figure 2. The porosity of the Ag nano paste joint at different temperatures.

The microstructure of the sintered joint after sintering at different temperatures for $120 \mathrm{~min}$ is displayed in Figure 3. The Ag nano paste joint featured a sandwich structure: bonding interface/bonding matrix/bonding interface. The interfacial layer was formed between the Ag nano paste and Au metallization on the substrate by interdiffusion, while 
the Ag NPs became a bonding matrix after sintering. However, the Ag NPs joined with each other to some degree. After sintering at $150{ }^{\circ} \mathrm{C}$ for $2 \mathrm{~h}$, many voids and cracks were observed at the bonding interface between the sintered nano paste layer and $\mathrm{Au}$ coating layer (Figure $3 a, b$ ), and the interface was clearly stratified. This result indicates that the interfacial metallurgical reaction was insufficient. A large number of pores was uniformly distributed in the sintered Ag nano paste bonding matrix; thus, a high porosity was measured, as mentioned above. With the increase in the sintering temperature $\left(200{ }^{\circ} \mathrm{C}\right)$, the number of pores decreased and the size increased, and a lower porosity was observed. The defects at the interface also decreased, which can be ascribed the sufficient elemental interdiffusion. When the sintering temperature reached $250^{\circ} \mathrm{C}$, the number of pores further decreased and the size further increased. However, no stratification was observed at the interface, and a uniform bonding layer with a thickness of $0.68 \mu \mathrm{m}$ was obtained, proving that sufficient interfacial reaction occurred. After sintering at $300^{\circ} \mathrm{C}$ for $2 \mathrm{~h}$, the pores in the sintered layer exhibited more obvious aggregation, resulting in a decrease in pore number and an increase in pore size. Compared with $200{ }^{\circ} \mathrm{C}$, a thicker bonding layer $(1.50 \mu \mathrm{m})$ was observed because of further interfacial elemental diffusion.

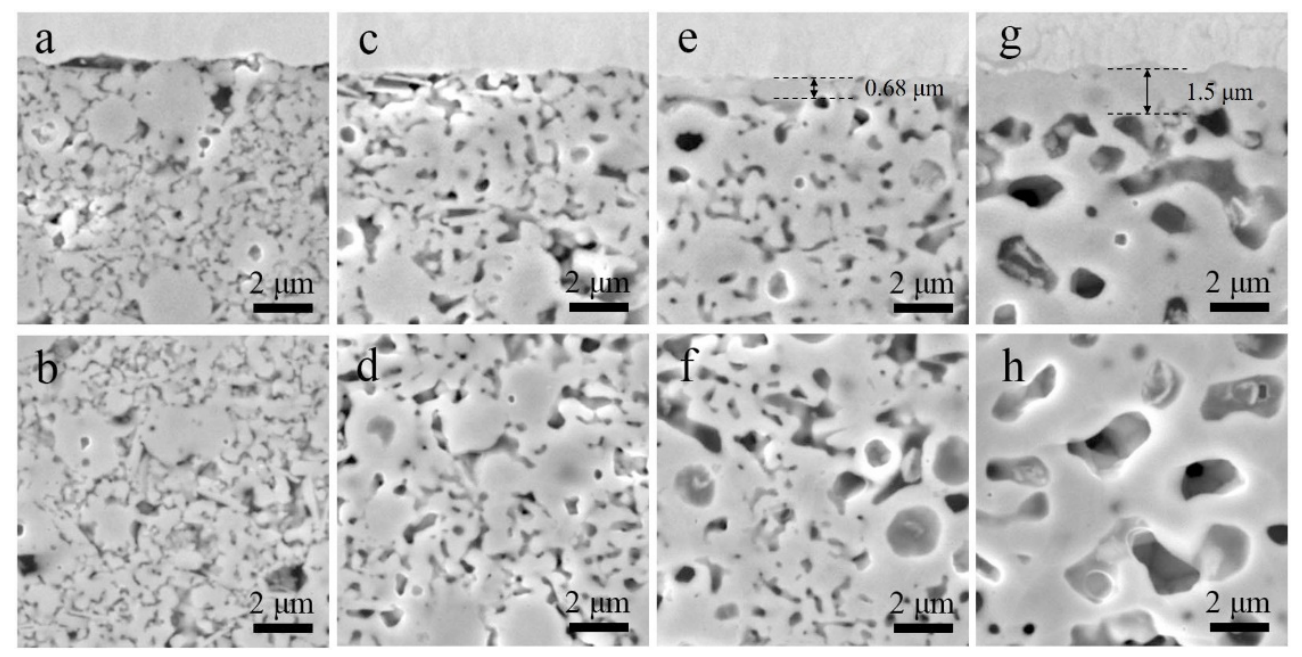

Figure 3. The microstructure of Ag nano paste joint on different temperatures after sintering for $2 \mathrm{~h}$ : (a) interfacial and (b) bonding microstructure at $150{ }^{\circ} \mathrm{C}$; (c) interfacial and (d) bonding microstructure at $200{ }^{\circ} \mathrm{C}$; (e) interfacial and (f) bonding microstructure at $250{ }^{\circ} \mathrm{C}$; (g) interfacial and (h) bonding microstructure at $300^{\circ} \mathrm{C}$.

\subsection{Mechanical Properties of Ag Nano Paste Joint}

The shear strength of the Ag nano paste joint was analyzed by using a Dage 4000 mechanical test machine, with a shear speed of $500 \mu \mathrm{m} / \mathrm{s}$ and a shear height of $20 \mu \mathrm{m}$. The testing standard is GJB 548B-2005. The change in the shear strength of the sintered joint with the sintering temperature is shown in Figure 4. It can clearly be observed that the shear strength gradually increased with the sintering temperature. After sintering at $150{ }^{\circ} \mathrm{C}$ for $2 \mathrm{~h}$, the shear strength was only $8.0 \pm 1.9 \mathrm{MPa}$, which did meet the requirements for practical usage in an electronic package. The shear strength exhibited a slight increase $(13.5 \pm 1.3 \mathrm{MPa})$ when the sintering temperature increased to $200{ }^{\circ} \mathrm{C}$. However, when the sintering temperature reached $250{ }^{\circ} \mathrm{C}$, a dramatic improvement in the shear strength $(33.7 \pm 3.2 \mathrm{MPa})$ was observed. When the sintering temperature was increased further, the shear strength only exhibited a negligible increase, indicating that the strong joint formed at $250{ }^{\circ} \mathrm{C}$. The improvement in shear strength is consistent with the evaluation of the microstructure in Figure 3. When the sintering temperature was low, the interfacial elemental diffusion was insufficient, and clear stratification was observed at the interface between the sintered Ag nano paste and Au metallization. By contrast, after sintering at high temperature, $\mathrm{Ag}$ and $\mathrm{Au}$ elements at the bonding interface were sufficiently dif- 
fused into each other, and a uniform and continuous interfacial layer formed. The strong metallurgical joint is beneficial for the increasing the shear strength.

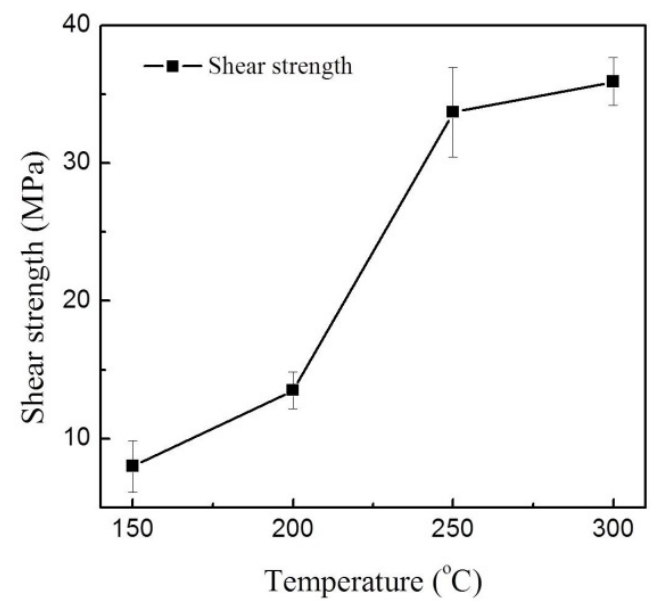

Figure 4. The shear strength of the Ag nano paste joint on different temperatures after sintering for $2 \mathrm{~h}$.

\subsection{Reliability of Ag Nano Paste Joint}

The bimodal Ag nano paste was utilized as an interconnection material to bond $\mathrm{SiC}$ die with copper substrate. The joints sintered under different temperatures were evaluated by using a thermal shocking (TS) test with a temperature range from $-65^{\circ} \mathrm{C}$ to $150{ }^{\circ} \mathrm{C}$. The TS experiment was conducted by a thermal shock tester, with an air heating medium. The four kinds of samples were maintained at $-65^{\circ} \mathrm{C}$ or $150{ }^{\circ} \mathrm{C}$ for $10 \mathrm{~min}$, the heating rate was $5{ }^{\circ} \mathrm{C} / \mathrm{min}$, and the changing time of the temperature was less than $1 \mathrm{~min}$. The TS tests were all performed for 50 cycles. Due to the coefficient of thermal expansion (CTE) mismatch between $\mathrm{SiC}\left(4.7 \times 10^{-6} \mathrm{~K}^{-1}\right)$ and $\mathrm{Cu}\left(17.5 \times 10^{-6} \mathrm{~K}^{-1}\right)$, there was huge thermal stress in the Ag nano paste joint during the TS testing; such stress can deteriorate the bonding joints. The SAM equipment, which can detect ultrasonic interfacial reflection, was used to test the fractures in the nano paste joint. If there is a higher density difference between the interfacial layers, the higher ultrasonic signal is received by the SAM transducer. When fractures form in the nano paste joint, there is a huge density difference between the metal material and the air in the fracture. Thus, the bright area marked by the red outline in the SAM image (Figure 5) could represent a fracture in the nano paste joint. For the samples obtained at $150{ }^{\circ} \mathrm{C}$, clear stratification could be observed at the interface; and the stratification percentage was $85 \%$ (Figure $5 \mathrm{a}$ ). The stratification percentage of the sample sintered at $200{ }^{\circ} \mathrm{C}$ gradually decreased to $67 \%$ after the same test (Figure $5 \mathrm{~b}$ ). Almost no stratification was observed in the samples obtained at $250{ }^{\circ} \mathrm{C}$ after 50 thermal cycles, and the stratification percentage was $5 \%$ (Figure $5 \mathrm{c}$ ). Unexpectedly, a higher stratification percentage (37\%) was measured in the sample sintered at $300{ }^{\circ} \mathrm{C}$ (Figure $5 \mathrm{~d}$ ).

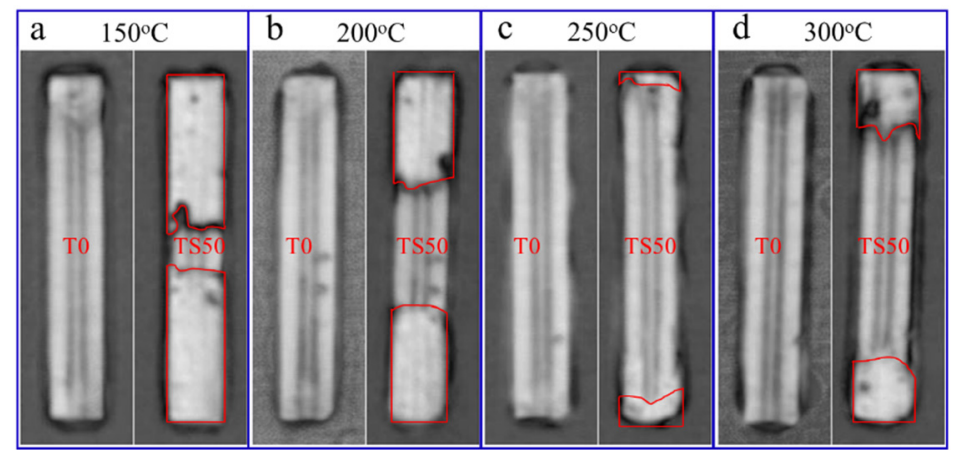

Figure 5. Comparison of the SAM images before and after the TS test at different temperatures: (a) $150{ }^{\circ} \mathrm{C}$; (b) $200{ }^{\circ} \mathrm{C}$; (c) $250{ }^{\circ} \mathrm{C}$; (d) $300^{\circ} \mathrm{C}$. 
To discover the reason why the sintered samples at different temperatures possess different resistance to thermal stress, we characterized the morphologies of the samples after the TS test. As demonstrated in Figure $6 \mathrm{a}$, for the samples obtained at $150{ }^{\circ} \mathrm{C}$, the cracks formed along the bonding interface between the Au coating layer and the Ag nano paste after the TS test. The cracks were generated from the stratification between the Au coating layer and the Ag nano paste. The interfacial layer, which is the weakest part and offers poor resistance to the thermal stress caused by quick temperature changes, was incomplete. For the samples obtained at $200{ }^{\circ} \mathrm{C}$, the interfacial defects between the $\mathrm{Au}$ coating and the Ag nano paste reduced, and their resistance against TS improved. At $250{ }^{\circ} \mathrm{C}$, a uniform and continuous bonding layer with a thickness of $0.68 \mu \mathrm{m}$ was obtained, and the resistance to temperature shock improved. As illustrated in Figure 6b, when sintering at $300{ }^{\circ} \mathrm{C}$, a $1.5 \mu \mathrm{m}$ bonding layer formed between the Au coating layer and the nano paste, and the cracks did not extend along the interface. However, the high temperature led to the aggregation of voids, forming large-sized pores, which are easy to crack, causing the extension of cracks in the Ag nano paste matrix (Figure 6b). As a result, the resistance against thermal shock decreased.
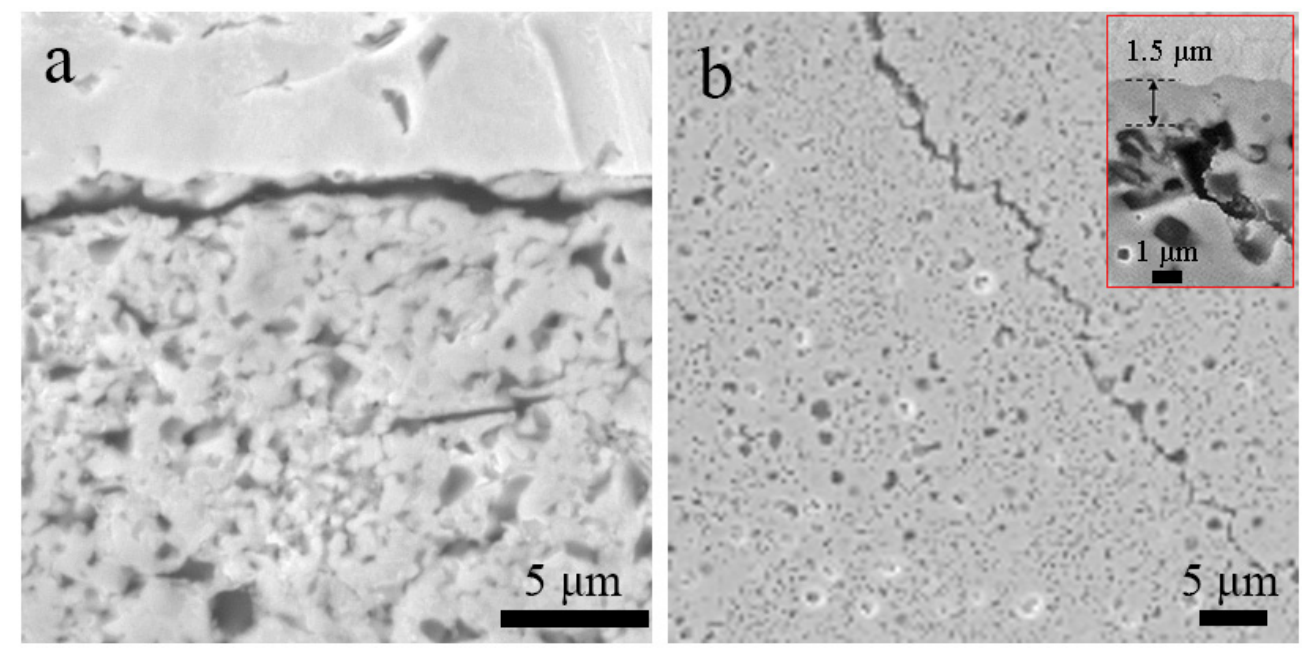

Figure 6. The cross-section image after TS test: (a) the fracture growth along interfacial layer after sintering at $150{ }^{\circ} \mathrm{C} ;(\mathbf{b})$ the fracture extension crossing Ag nano paste matrix after sintering at $300{ }^{\circ} \mathrm{C}$.

\section{Conclusions}

Using pressure-less sintering, Ag nano paste joints were prepared. The microstructure observation illustrates that temperature improvement and time extension can reduce porosity in Ag nano paste bonding matrices and defects in the bonding interface, due to a faster atomic diffusion rate and sufficient atomic diffusion. When the temperature rises beyond $250^{\circ} \mathrm{C}$, a complete bonding interface between the $\mathrm{Ag}$ nano paste matrix and the $\mathrm{Au}$ metallization on the substrate is formed. From $150{ }^{\circ} \mathrm{C}$ to $250^{\circ} \mathrm{C}$, the shear strength of joints increases clearly from $8.0 \pm 1.9 \mathrm{MPa}$ to $33.7 \pm 3.2 \mathrm{MPa}$, while further increases in sintering temperature produce slight improvements in the shear strength. By conducting TS tests, the resistance of $\mathrm{Ag}$ nano paste joints to thermal stress was investigated. From $150{ }^{\circ} \mathrm{C}$ to $30{ }^{\circ} \mathrm{C}$, the $\mathrm{Ag}$ nano paste joint sintered at $250{ }^{\circ} \mathrm{C}$ displayed the highest reliability (stratification percentage of $5 \%$ ), as the joint exhibited the highest resistance to thermal stress. When the sintering temperature was lower than $250^{\circ} \mathrm{C}$, the bonding interface was incomplete and demonstrated fracture defects due to insufficient interfacial atomic diffusion. At $300{ }^{\circ} \mathrm{C}$, the voids in the bonding matrix aggregated excessively to form large-sized pores. Thus, instead of further enhancement in thermal stress resistance, the stratification percentage increased to $37 \%$. In summary, after sintering at $250^{\circ} \mathrm{C}$, Ag nano paste joints form complete interfacial layers, and the pores in the bonding matrix are small and uniformly distributed, providing excellent resistance to crack extension. 
Author Contributions: Conceptualization, D.Y.; methodology, D.Y.; software, Y.H.; validation Y.T.; investigation, D.Y.; data curation, Y.H.; writing—original draft preparation, D.Y.; writing-review and editing, Y.T.; supervision, Y.T.; project administration, Y.T.; funding acquisition, Y.T. All authors have read and agreed to the published version of the manuscript.

Funding: The authors are grateful for financial from the "Heilongiiang Touyan Team".

Institutional Review Board Statement: Not applicable.

Informed Consent Statement: Not applicable.

Data Availability Statement: Available on request.

Conflicts of Interest: The authors declare no conflict of interest.

\section{References}

1. Paknejad, S.A.; Mannan, S.H. Review of silver nanoparticle based die attach materials for high power/temperature applications. Microelectron. Reliab. 2017, 70,1-11. [CrossRef]

2. Bai, J.G.; Lu, G.Q. Thermomechanical reliability of low-temperature sintered silver die attached SiC power device assembly. IEEE Trans. Device Mater. Reliab. 2006, 6, 436-441. [CrossRef]

3. Hornberger, J.; Lostetter, A.; Olejniczak, K.; McNutt, T.; Lal, S.M.; Mantooth, A. Siliconcarbide (SiC) semiconductor power electronics for extreme high-temperature environments. In Proceedings of the 2004 IEEE Aerospace Conference Proceedings (IEEE Cat. No.04TH8720), Big Sky, MT, USA, 6-13 March 2004; Volume 4, pp. 2538-2555.

4. Buttay, C.; Planson, D.; Allard, B.; Bergogne, D.; Bevilacqua, P.; Joubert, C.; Raynaud, C. State of the art of high temperature power electronics. Mater. Sci. Eng. B 2011, 176, 283-288. [CrossRef]

5. Tollefsen, T.A.; Løvvik, O.M.; Aasmundtveit, K.; Larsson, A. Effect of temperature on the die shear strength of a Au-Sn SLID bond. Metall. Mater. Trans. A 2013, 44, 2914-2916. [CrossRef]

6. Bai, J.G.; Zhang, Z.Z.; Calata, J.N.; Lu, G.Q. Low-temperature sintered nanoscale silver as a novel semiconductor device-metallized substrate interconnect material. IEEE Trans. Compon. Packag. Technol. 2006, 29, 589-593. [CrossRef]

7. Wang, S.; Ji, H.; Li, M.; Wang, C. Fabrication of interconnects using pressureless low temperature sintered Ag nanoparticles. Mater. Lett. 2012, 85, 61-63. [CrossRef]

8. Li, J.; Johnson, C.M.; Buttay, C.; Sabbah, W.; Azzopardi, S. Bonding strength of multiple SiC die attachment prepared by sintering of Ag nanoparticles. J. Mater. Process. Technol. 2015, 215, 299-308. [CrossRef]

9. Akada, Y.; Tatsumi, H.; Yamaguchi, T.; Hirose, A.; Morita, T.; Ide, E. Interfacial bonding mechanism using silver metallo-organic nanoparticles to bulk metals and observation of sintering behavior. Mater. Trans. 2008, 49, 1537-1545. [CrossRef]

10. Wei, D.; Qian, W. Facile synthesis of Ag and Au nanoparticles utilizing chitosan as a mediator agent. Colloids Surf. B Biointerfaces 2008, 62, 136-142. [CrossRef] [PubMed]

11. Xie, Y.; Wang, Y.; Mei, Y.; Xie, H.; Zhang, K.; Feng, S.; Lu, G.Q. Rapid sintering of nano-Ag paste at low current to bond large area $\left(>100 \mathrm{~mm}^{2}\right.$ ) power chips for electronics packaging. J. Mater. Process. Technol. 2018, 255, 644-649. [CrossRef]

12. Buttay, C.; Riva, R.; Allard, B.; Locatelli, M.L.; Bley, V. Packaging with double-side cooling capability for SiC devices, based on silver sintering. In Proceedings of the 44th Annual Conference of the IEEE Industrial Electronics Society, Washington, DC, USA, 21-23 October 2018; pp. 5753-5759.

13. Yang, F.; Hu, B.; Peng, Y.; Hang, C.; Chen, H.; Lee, C.; Li, M. Ag microflake-reinforced nano-Ag paste with high mechanical reliability for high-temperature applications. J. Mater. Sci. Mater. Electron. 2019, 30, 5526-5535. [CrossRef] 